\title{
X-Ray crystallographic and computational study on uranyl- salophen complexes bearing nitro groups $\uparrow$
}

\author{
Arto Valkonen, ${ }^{a}$ Giuseppe M. Lombardo, ${ }^{b}$ Kari Rissanen, a Francesco Punzo*b \\ and Massimo Cametti*c
}

In the solid state, salophen- $\mathrm{UO}_{2}$ complexes bearing one, two, or three $\mathrm{NO}_{2}$ groups lack the pronounced ligand curvature that represents a structural hallmark for this class of compounds. A detailed structural study based on single-crystal $\mathrm{X}$-ray crystallography and computational methods, comprising molecular dynamics, gas-phase Hartree Fock, and DFT calculations, was carried out to investigate the coordination properties of the uranyl cation.

\section{Introduction}

Salophens and salens represent an old and extremely common class of diimino tetradentate ligands that are extensively employed in coordination chemistry. ${ }^{1}$ The reaction between the salophen ligand and the uranyl $\left(\mathrm{UO}_{2}{ }^{2+}\right)$ dication affords a kinetically robust neutral complex, 1 (Fig. 1a), in which the metal centre adopts a pentagonal bipyramidal coordination, with its two oxygen atoms at the apical positions. As indicated by the crystal structure of $\mathbf{1} \cdot \mathbf{M e C N}$, determined by X-ray diffraction (XRD), as depicted in Fig. $1 \mathrm{~b},{ }^{2}$ four out of five equatorial positions are occupied by the donor atoms of the ligand $\mathrm{N}_{2} \mathrm{O}_{2}$. The fifth coordination site remains available for additional Lewis acid-base interaction with the solvent (an acetonitrile molecule in this case) or with any other suitable Lewis basic substrate. For this reason, over the past decade or so, salophen- $\mathrm{UO}_{2}$ complexes have received significant attention and they have been successfully employed as receptors for anionic and ion-pair substrates ${ }^{2,3}$ and as electrophilic catalysts. ${ }^{4}$ More generally, interest in actinide-ligand complexes has originated due to the yet unsolved problems related to the disposal of radioactive wastes generated by nuclear fuels. ${ }^{5}$ Uranyl ion constitutes the most stable form of hexavalent uranium and, therefore, the design of efficient and selective ligands for $\mathrm{UO}_{2}{ }^{2+}$ ion currently engages the efforts of many research groups. ${ }^{6}$ These initiatives should not forgo without reaching an in-depth understanding of the coordination geometry requirements of uranyl ion. Salophen- $\mathrm{UO}_{2}$ complexes represent optimal model compounds. From a structural point of

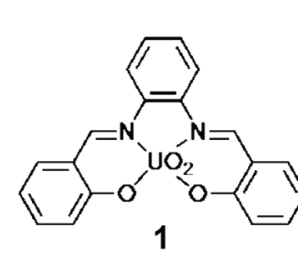

a)

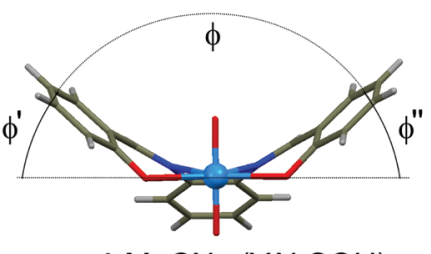

b)
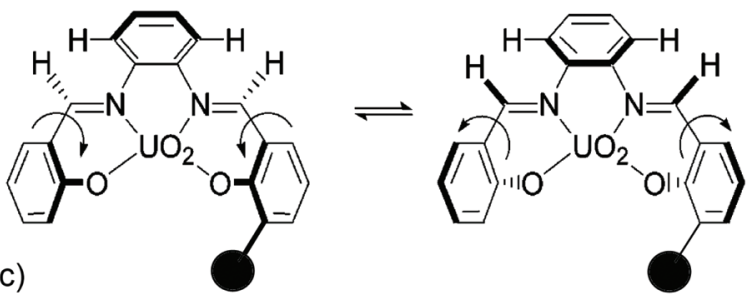

Fig. 1 (a) Molecular formula of complex 1. (b) Crystal structure of 1. $\mathrm{MeCN}$ (YALSOU); colour code: $\mathrm{C}=$ grey, $\mathrm{H}=$ light grey, $\mathrm{N}=$ blue, $\mathrm{O}=$ red, and $\mathrm{U}=$ cyan; the uranyl coordinated $\mathrm{MeCN}$ solvent molecule, contributing to the definition of the pentagonal bipyramidal coordination, was omitted for clarity; geometrical parameters $\phi, \phi^{\prime}$, and $\phi^{\prime \prime}$ are shown; (c) flipping motion between the two enantiomeric forms in the case of a $\mathrm{UO}_{2}$-complex made with a generic non-symmetrically substituted salophen ligand.

${ }^{a}$ Department of Chemistry, Nanoscience Center, University of Jyväskylä, P.O. Box 35, 40014 Jyväskylä, Finland

${ }^{b}$ Dipartimento di Scienze del Farmaco, Sezione Chimica, Università di Catania, Viale Andrea Doria, 695125 Catania, Italy.E-mail:fpunzo@unict.it ${ }^{c}$ Department of Chemistry, Materials and Chemical Engineering "Giulio Natta" Politecnico di Milano, Via Luigi Mancinelli 7, 20131 Milano, Italy. E-mail: massimo.cametti@polimi.it

$\dagger$ Electronic supplementary information (ESI) available: Additional crystallographic details and tables, additional HOMO-LUMO analysis; table with full data set for $\Phi$ angles; structure of $\mathrm{Mg}$-salophen complex; ${ }^{1} \mathrm{H}$ - and ${ }^{13} \mathrm{C}-\mathrm{NMR}$ spectra. CCDC 1519432-1519437. For ESI and crystallographic data in CIF or other electronic format see DOI: 10.1039/c6dt04773d 
view, a highly puckered, non-planar conformation of the molecular frame (see Fig. 1b) represents the hallmark of salophen$\mathrm{UO}_{2}$ complexes. Deviation from planarity may have important consequences since, as reported by Mandolini et al., ${ }^{7}$ salophen- $\mathrm{UO}_{2}$ complexes fabricated with non-symmetrical ligands exhibit inherent chirality and thus they may exist as pairs of enantiomers. A process termed as flipping motion (Fig. 1c), which is usually fast, interconverts one enantiomer into other. Therefore, the chirality of the sesalophen- $\mathrm{UO}_{2}$ complexes derives from the combination of the non-symmetric structure of the ligand and the overall curvature of the complex, leading to the absence of symmetry elements. This deviation from planarity, which is commonly attributed to the large ionic radius of the $\mathrm{UO}_{2}$ center, can be easily measured. This was previously carried out by introducing the parameters $\delta$ and $\delta^{\prime}$ relative to the two halves of the complex, $\delta=\delta^{\prime}=0$ being the case for planar species; ${ }^{8}$ however, herein, we introduced a novel parameter, the angle $\phi$, which represents the angle formed by the planes defined by two lateral aromatic rings. We believed that this parameter could more intuitively describe the overall curvature of the system (Fig. 1b). The parameters angle $\phi^{\prime}$ and $\phi^{\prime \prime}$ (and their combination $\left|\phi^{\prime}-\phi^{\prime \prime}\right|$ ) were also introduced (Fig. 1b). They represent the angle formed by the planes defined by each of two lateral aromatic rings with the $\mathrm{UO}_{2}$ equatorial coordination plane $\mathrm{e}^{9}$ and relate to the symmetry of the ligand (vide infra). In the case of $\mathbf{1 \cdot M e C N}$ (YALSOU), $\phi$ is equal to $98.42^{\circ}$ (for a completely planar system $\phi=180^{\circ}$ ), indicating a high degree of curvature. Moreover, since $\phi^{\prime}=\phi^{\prime \prime}=$ $40.79^{\circ}\left(\left|\phi^{\prime}-\phi^{\prime \prime}\right|=0\right)$, the complex is perfectly symmetric. The presence of a central benzene ring is crucial to the curvature since it forces a more rigid conformation of the ligand. Note that salen derivatives, in which the central aromatic (o-phenylenediamine) ring is replaced with a two-carbon aliphatic chain (ethylenediamine), display more flexibility and thus exhibit more planar conformations. ${ }^{10}$

In the course of our studies aimed at using salophen- $\mathrm{UO}_{2}$ as a receptor for anions and ion-pairs, ${ }^{2,3}$ we synthesized complex 2, which possesses a $\mathrm{NO}_{2}$ group on the central benzene ring. It is known that the $\mathrm{NO}_{2}$ group has a strong electron-withdrawing character, a fairly high reactivity, and a significant influence on the overall molecular properties. ${ }^{11}$ Single crystals of 2.EtOH were obtained by slow evaporation of a concentrated solution of 2 in EtOH and analyzed by XRD. Considering the minimal structural modification with respect to $\mathbf{1} \cdot \mathbf{M e C N}$, it was found that $\mathbf{2} \cdot \mathbf{E t O H}$ has peculiar structural features in the solid state. Indeed, the abovementioned curvature of the salophen organic framework, a classical characteristic that is present in all the reported salophen- $\mathrm{UO}_{2}$ complexes (vide infra), is severely reduced $\left(\phi=127.13^{\circ}\right)$. Moreover, we noticed a strong reduction in the symmetry between the two halves of the complex, with the planarity being significantly more pronounced on the side that is opposite to the additional $\mathrm{NO}_{2}$ group $\left(\phi^{\prime}=2.92, \phi^{\prime \prime}=53.51\right.$ and $\left|\phi^{\prime}-\phi^{\prime \prime}\right|=$ $50.59^{\circ}$ ). A visual comparison between the structures of complexes 1.MeCN (YALSOU) ${ }^{2}$ and 2.EtOH has been provided in Fig. 2. The structural difference is indeed striking.
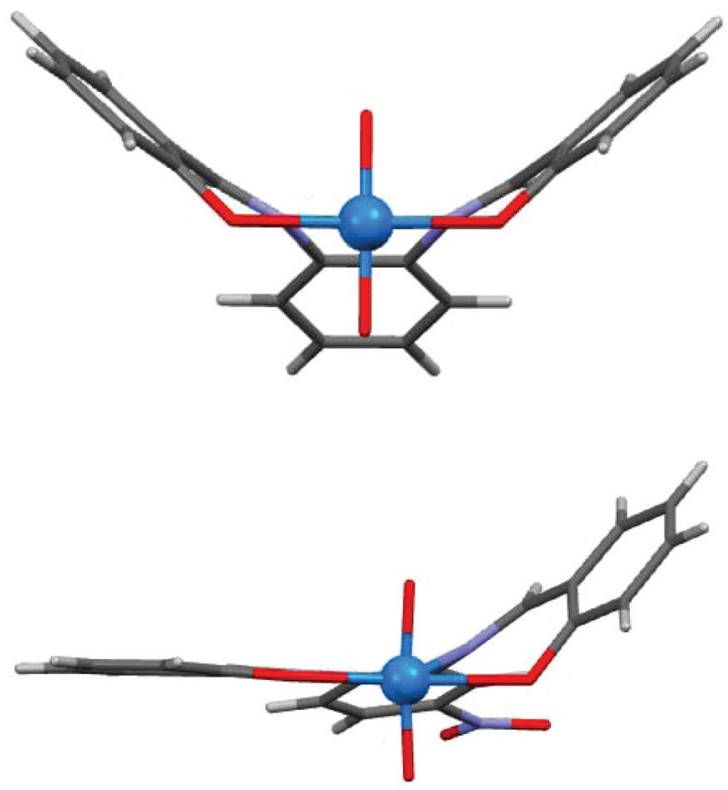

Fig. 2 Crystal structures of the complexes 1-MeCN (YALSOU) (top) and 2.EtOH (bottom). $\mathrm{UO}_{2}$-coordinated solvent molecules are omitted for clarity. Colour code: $\mathrm{C}=$ grey, $\mathrm{H}=$ light grey, $\mathrm{N}=$ blue, $\mathrm{O}=$ red, and $\mathrm{U}=$ cyan.

Intrigued by this discovery, we initiated a systematic experimental and computational study aimed at ascertaining whether the presence of one or more $\mathrm{NO}_{2}$ groups would have an impact on the geometry of the salophen moiety when complexed with the $\mathrm{UO}_{2}$ cation and devising a possible explanation for this. Thus, complexes 3 and 4, bearing additional $\mathrm{NO}_{2}$ groups, and $\mathbf{5}$ and $\mathbf{6}$, with extended aromatic surfaces, were synthesized and characterized. Single crystals were then obtained and structurally characterized by XRD analyses.

Herein, we report the outcome of our study derived from the integration of experimental XRD analyses on single crystals of six novel complexes (2-MeOH, 2-EtOH, 3·MeCN, 4-DMF, $\mathbf{5} \cdot \mathbf{H}_{2} \mathbf{O}$, and 6.DMF), Cambridge Structural Database (CSD) analyses on previously reported salophen- $\mathrm{UO}_{2}$ complexes, and an extensive theoretical study comprising molecular dynamics (MD) under periodic boundary conditions, gas-phase Hartree Fock (HF) and DFT calculations, and HOMO-LUMO analysis. The entire set of the experimental and computational data obtained in this study was analysed considering the structure of $\mathbf{1} \cdot \mathbf{M e C N}$ (YALSOU), ${ }^{2}$ which bears no $\mathrm{NO}_{2}$ group, is symmetric, and represents the optimal comparison. An understanding of the reason for the evident and unprecedented distortion in response to a definite structural modification could indeed be valuable in defining the coordination requirements of the uranyl dication. In this regard, the application of quantum mechanical calculations to gain insights into the electronic structure of actinide compounds has been extensively reviewed. ${ }^{12}$ However, studies that combine and integrate experimental and computational analyses have rarely been reported. 


\section{Experimental methods}

\subsection{Synthesis}

General procedure for the preparation of the salophen- $\mathrm{UO}_{2}$ complexes 2-6. To a refluxing methanol solution of the corresponding aldehyde $(0.01 \mathrm{~mol}$ in $100 \mathrm{~mL})$, aromatic diamine was added (0.005 mol) under stirring. In some cases, a yellow precipitate was formed. Then, $0.005 \mathrm{~mol}$ of $\mathrm{UO}_{2}(\mathrm{OAc})_{2}$ was added. The solution turned orange-red and, if not present before, abundant precipitate appeared. The flask was maintained at refluxing temperature $\left(c a .65{ }^{\circ} \mathrm{C}\right)$ for $5 \mathrm{~h}$ and then left to cool down overnight at r.t. The precipitate was filtered and washed with cold methanol ( $\left.\mathrm{ca} .5^{\circ} \mathrm{C}\right)$ and diethyl ether and then dried under vacuum. Yields were in the range of $60-85 \%$.

Salophen-UO $\mathrm{U}_{2}$ complex 2. ${ }^{1} \mathrm{H}$ NMR (500 MHz, DMSO-d6): $\delta 9.76(\mathrm{~s}, 1 \mathrm{H}), 9.68(\mathrm{~s}, 1 \mathrm{H}), 8.67(\mathrm{~d}, J=2.4 \mathrm{~Hz}, 1 \mathrm{H}), 8.38(\mathrm{dd}, J=$ 8.8, 2.4 Hz, 1H), $8.03(\mathrm{~d}, J=8.8 \mathrm{~Hz}, 1 \mathrm{H}), 7.90-7.78(\mathrm{~m}, 2 \mathrm{H})$, $7.67(\mathrm{dd}, J=8.5,1.6 \mathrm{~Hz}, 2 \mathrm{H}), 7.02(\mathrm{dd}, J=8.3,3.3 \mathrm{~Hz}, 2 \mathrm{H}), 6.75$ (t, $J=7.4 \mathrm{~Hz}, 2 \mathrm{H}) ; \delta{ }^{13} \mathrm{C}$ NMR (126 MHz, DMSO-d6): 170.58, $170.18,169.47,169.06,151.87,147.28,146.79,137.17,136.71$, 136.49, 136.37, 123.99, 123.91, 123.36, 121.40, 120.87, 120.68, 116.93, 116.85, 115.75. ESI-MS: calcd for $\mathrm{C}_{20} \mathrm{H}_{13} \mathrm{~N}_{3} \mathrm{O}_{6} \mathrm{UCl}=$ 664.10, found $=664.3[\mathrm{M}-\mathrm{Cl}]^{-}$; elem. anal.: calc. for $\mathrm{C}_{21} \mathrm{H}_{17} \mathrm{~N}_{3} \mathrm{O}_{7} \mathrm{U}$ (2-MeOH): C, 38.13; N, 6.35; H, 2.59; found: C, $38.3 ; \mathrm{N}, 6.2 ; \mathrm{H}, 2.4 \%$; yield $=75 \%$.

Salophen- $\mathrm{UO}_{2}$ complex 3. ${ }^{1} \mathrm{H}-\mathrm{NMR}$ (DMSO- $d 6,500 \mathrm{MHz}$ ): $\delta 9.91(\mathrm{~s}, 2 \mathrm{H}), 8.93(\mathrm{~d}, J=3.0 \mathrm{~Hz}, 2 \mathrm{H}), 8.46(\mathrm{dd}, J=9.3,3.0 \mathrm{~Hz}$, 2H), $7.93(\mathrm{~m}, 2 \mathrm{H}), 7.65(\mathrm{~m}, 1 \mathrm{H}), 7.21(\mathrm{~d}, J=9.3 \mathrm{~Hz}, 1 \mathrm{H}) ;{ }^{13} \mathrm{C}$ NMR (126 MHz, DMSO-d6): $\delta$ 174.67, 166.89, 146.09, 137.33, 132.90, 130.57, 129.66, 123.25, 121.58, 120.83. ESI-MS: calcd for $\mathrm{C}_{20} \mathrm{H}_{12} \mathrm{~N}_{4} \mathrm{O}_{8} \mathrm{UCl}=709.09$, found $=709.3[\mathrm{M}-\mathrm{Cl}]^{-}$; elem. anal.: calc. for $\mathrm{C}_{21} \mathrm{H}_{16} \mathrm{~N}_{4} \mathrm{O}_{9} \mathrm{U}$ (3-MeOH): C, 35.71; N, 7.93; H, 2.28; found: C, 36.1; N, 7.8; H, 2.1\%; yield $=70 \%$.

Salophen- $\mathrm{UO}_{2}$ complex 4. ${ }^{1} \mathrm{H}$ NMR (400 MHz, DMSO-d6) $\delta 10.05(\mathrm{~s}, 1 \mathrm{H}), \delta 9.98(\mathrm{~s}, 1 \mathrm{H}), \delta 8.96(\mathrm{dd}, J=2.9,0.9 \mathrm{~Hz}, 2 \mathrm{H})$, $8.87(\mathrm{~d}, J=2.4 \mathrm{~Hz}, 1 \mathrm{H}), 8.58-8.42(\mathrm{~m}, 3 \mathrm{H}), 8.17$ (d, $J=8.9 \mathrm{~Hz}$, $1 \mathrm{H}), 7.23$ (dd, $J=9.3,1.9 \mathrm{~Hz}, 2 \mathrm{H})$; ${ }^{13} \mathrm{C}$ NMR (101 MHz, DMSOd6) $\delta 175.06,174.85,170.01,169.57,151.06,147.51,146.73$, $137.51,137.47,133.54,133.49,131.33,131.05,124.21$, 122.97, 122.14, 121.91, 121.75, 116.52. ESI-MS: calcd for $\mathrm{C}_{20} \mathrm{H}_{11} \mathrm{~N}_{5} \mathrm{O}_{10} \mathrm{UCl}=754.07$, found $754.3[\mathrm{M}-\mathrm{Cl}]^{-}$; elem. anal.: calc. for $\mathrm{C}_{21} \mathrm{H}_{15} \mathrm{~N}_{5} \mathrm{O}_{11} \mathrm{U}$ : (4-MeOH) C, 33.57; N, 9.32; H, 2.01; found: C, 34.1; N, 9.2; H, 1.9\%; yield $=60 \%$.

Salophen- $\mathrm{UO}_{2}$ complex 5. ${ }^{1} \mathrm{H}$ NMR (400 MHz, DMSO-d6) $\delta 10.32(\mathrm{~s}, 1 \mathrm{H}), 10.24(\mathrm{~s}, 1 \mathrm{H}), \delta 8.71(\mathrm{~d}, J=2.4 \mathrm{~Hz}, 1 \mathrm{H}), 8.40(\mathrm{t}$, $J=8.7 \mathrm{~Hz}, 2 \mathrm{H}), 8.34(\mathrm{dd}, J=8.8,2.4 \mathrm{~Hz}, 1 \mathrm{H}), 8.24$ (dd, $J=9.1$, $6.3 \mathrm{~Hz}, 2 \mathrm{H}), 8.09$ (d, $J=8.8 \mathrm{~Hz}, 1 \mathrm{H}), 7.87$ (d, $J=7.8 \mathrm{~Hz}, 2 \mathrm{H})$, $7.58(\mathrm{t}, J=7.1 \mathrm{~Hz}, 2 \mathrm{H}), 7.41-7.35(\mathrm{~m}, 3 \mathrm{H}), 7.41-7.28(\mathrm{~m}, 4 \mathrm{H})$; ${ }^{13} \mathrm{C}$ NMR (101 MHz, DMSO- $\left.d 6\right) \delta$ 172.71, 172.02, 162.41, 162.37, 152.67, 147.86, 146.52, 138.54, 137.90, 134.50, 128.80, 128.68, 128.14, 127.92, 127.03, 124.16, 124.07, 123.20, 123.04, $121.55,121.34,121.22,115.87,114.99,114.79$. ESI-MS: calcd for $\mathrm{C}_{28} \mathrm{H}_{17} \mathrm{~N}_{3} \mathrm{O}_{6} \mathrm{UCl}=764.13$, found $764.4[\mathrm{M}-\mathrm{Cl}]^{-}$; elem. anal.: calc. for $\mathrm{C}_{29} \mathrm{H}_{21} \mathrm{~N}_{3} \mathrm{O}_{7} \mathrm{U}$ : (5-MeOH) C, 45.74; N, 5.52; H, 2.78; found: C, 46.3; N, 5.7; H, 2.9\%; yield $=85 \%$.
Salophen-UO $\mathrm{UO}_{2}$ complex 6. ${ }^{1} \mathrm{H}$ NMR (400 MHz, DMSO-d6) $\delta 10.20(\mathrm{~s}, 1 \mathrm{H}), 8.34(\mathrm{~d}, J=8.5 \mathrm{~Hz}, 1 \mathrm{H}), 8.19(\mathrm{~d}, J=9.1 \mathrm{~Hz}, 1 \mathrm{H})$, 7.90-7.80 (m, 2H), 7.62-7.48 (m, 2H), 7.37 (d, $J=9.1 \mathrm{~Hz}, 1 \mathrm{H})$, $7.31(\mathrm{t}, J=7.4 \mathrm{~Hz}, 1 \mathrm{H}) ;{ }^{13} \mathrm{C}$ NMR (101 MHz, DMSO-d6) $\delta 171.31,159.94,147.33,137.02,134.43,128.66,128.39$, 127.81, 126.97, 124.13, 122.80, 121.22, 120.20, 114.63. ESI-MS: calcd for $\mathrm{C}_{28} \mathrm{H}_{18} \mathrm{~N}_{2} \mathrm{O}_{4} \mathrm{UCl}=719.15$, found $719.2[\mathrm{M}-\mathrm{Cl}]^{-}$; elem. anal.: calc. for $\mathrm{C}_{28} \mathrm{H}_{20} \mathrm{~N}_{2} \mathrm{O}_{5} \mathrm{U}\left(6-\mathrm{H}_{2} \mathrm{O}\right)$ : C, 47.87; N, 3.99; $\mathrm{H}, 2.87$; found: $\mathrm{C}, 48.2 ; \mathrm{N}, 4.2 ; \mathrm{H}, 2.6 \%$; yield $=85 \%$.

Plots of the ${ }^{1} \mathrm{H}$ - and ${ }^{13} \mathrm{C}-\mathrm{NMR}$ spectra can be found in Fig. S11 and S12 (ESI $\dagger$ ). Elemental analyses were carried out using a Costech ECS instrument mod. 4010.

\subsection{X-ray crystallography}

Single crystals of complexes $\mathbf{2} \cdot \mathbf{M e O H}, \mathbf{2} \cdot \mathbf{E t O H}, \mathbf{3} \cdot \mathbf{M e C N}, \mathbf{4} \cdot \mathbf{D M F}$, $\mathbf{5} \cdot \mathbf{H}_{2} \mathrm{O}$, and 6.DMF were obtained by slow evaporation of a concentrated solution of each species in a given solvent $(\mathrm{MeOH}$, EtOH, MeCN, or DMF; acetone for $\mathbf{5} \cdot \mathbf{H}_{2} \mathbf{O}$ ). Single-crystal X-ray data were obtained at 123(2) K via a Bruker-Nonius Kappa CCD diffractometer with an APEX-II detector and monochromatized Mo-K $\alpha(\lambda=0.71073 \AA)$ radiation was utilized. For additional details see the ESI. $\dagger$

\subsection{In silico studies}

Quantum mechanical calculations. Hartree-Fock (HF) and density functional theory (DFT) calculations were performed using the Gaussian09 package. For the DFT, Grimme's B97 functional with the D3 dispersion scheme (B97D3 keyword) was used. $^{13}$ In all the calculations, the Stuttgart/Dresden effective core potential (ECP) basis set (SSD keyword) ${ }^{14}$ was used for the $\mathrm{U}$ atom, and for the other elements $(\mathrm{H}, \mathrm{C}, \mathrm{N}$, and O), the all-electron 6-311G(d,p) basis set was used. Geometric optimizations were carried out via the program's default (Berny algorithm) procedure. ${ }^{15}$

Force field calculations. The molecular mechanics (MM) and molecular dynamics (MD) calculations were performed via the Materials Studio package (Accelrys Software Inc., San Diego) using the Discover module with the implemented AMBER force field (FF), ${ }^{16}$ which was augmented to consider the uranyl moiety $\left(\mathrm{UO}_{2}\right){ }^{17}$ The electrostatic charges for each atom of the uranyl moiety were set to 1.430 for $\mathrm{U}$ and -0.412 for $\mathrm{O}$, whereas for the $\mathrm{NO}_{2}$ group, electrostatic charge for $\mathrm{N}$ was set to 0.571 and that for the two attached $\mathrm{O}$ was set to -0.380 , and for the carbon atom attached to the nitro group, the electrostatic charge was set to 0.189 . The charges of the nitrogen atoms of salophen, which coordinate the uranyl group, were set to -0.340 , whereas for the attached carbon atoms, electrostatic charges for the aromatic carbons were set to 0.204 and those for the others were set to 0.219 .

For the remaining atoms, the charges were set according to the AMBER's FF rules, as implemented in the Materials Studio. Settings of the non-bond (NB) interactions were different for the electrostatic and dispersion interactions. For the vdW term, an atom-based summation method (cut-off $=15.50$, spline width $=5.00$, and buffer 
width $=2.00 \AA$ ) with a long-range energy correction (tail correction $=15.50 \AA$ ) was used, whereas for the coulomb term, the Ewald summation method (accuracy $=0.0001 \mathrm{kcal} \mathrm{mol}^{-1}$ and update width $=5.00 \AA$ ) with the dielectric value $\varepsilon$ set to 1.0 was used.

Protocols. The MD simulations at a constant number of particles, pressure, and temperature (NPT ensemble) were carried out starting from the energy-minimized structures. In these simulations, periodic boundary conditions (PBC) with $P=$ $0.0 \mathrm{GPa}, T=123 \mathrm{~K}$, and an integration time-step of $0.001 \mathrm{ps}$ were used for all the runs. To allow the cell to change both the shape and volume, we used the Parrinello ${ }^{16}$ pressure control method, whereas the Berendsen thermostat with the default decay constant of 0.01 ps was used to control the temperature. ${ }^{18}$ Transients of $1.5 \mathrm{~ns}$, after a 500 ps equilibration period, were obtained with a sampling interval of 200 time-steps. The smart minimizer of the Discover module was used to optimize the energy to the gradient of $0.1 \mathrm{kcal} \mathrm{mol}^{-1}$ for the structures to be submitted to MD simulation.

Modeling. The structural models used to perform the MD simulations and the HF/DFT calculations were generated from the single-crystal structure (unit cells and atomic fractional coordinates), as reported in the cif files available as ESI. $\dagger$ For $\mathrm{MD}$, to relax any symmetry constraints, P1 periodic structural models of each compound were used. These were constructed from the fractional coordinates of each atom in the unit cell together with their $P \overline{1}$ symmetry related counterparts. In this manner, all the atoms in the model unit cells could independently move from one another. The model unit cells were replicated along the directions of the three axes to attain bigger supercells, 3 times along $a, 2$ times along $b$, and 2 times along $c$ for compounds $\mathbf{2} \cdot \mathbf{M e O H}, 2 \cdot \mathbf{E t O H}, 4 \cdot \mathbf{D M F}$, and $\mathbf{5} \cdot \mathbf{H}_{2} \mathbf{O}$, and 2 times along $a, 2$ times along $b$, and 2 times along $c$ for compound $3 \cdot \mathbf{M e C N}$, to reduce possible dimensional effects. Thus, the MD simulation cells for each model have the dimensions as reported in Table S3 (ESI $\dagger$ ), with 24 independent molecules for compounds $\mathbf{2} \cdot \mathbf{M e O H}, \mathbf{2} \cdot \mathbf{E t O H}, \mathbf{4} \cdot \mathbf{D M F}$, and $\mathbf{5} \cdot \mathbf{H}_{2} \mathrm{O}$ and 16 for $3 \cdot \mathbf{M e C N}$.

Moreover, for $\mathbf{2} \cdot \mathbf{M e O H}$ and $\mathbf{4} \cdot \mathbf{D M F}$, as there are atoms that have two possible positions with different fractional occupancies in the cif files, the supercells were constructed considering their occupancy ratios. For 2-MeOH $(Z=2)$, since the supercell contained a total of $Z \times 3 \times 2 \times 2=24$ molecular units, there were 3 molecular units (randomly chosen from the 24 molecular units, $3 / 24=0.125$ ) with 0.123 occupancy positions and 21 molecular units with 0.877 occupancy positions $(21 / 24=0.875)$; for compound $4 \cdot$ DMF, $(Z=2)$, the supercell still contained a total of $Z \times 3 \times 2 \times 2=24$ molecular units, whereas there were 9 molecular units (randomly chosen from the 24 molecular units, $9 / 24=0.375$ ) with 0.383 occupancy positions and 15 units with 0.617 occupancy positions $(15 / 24=$ $0.625)$.

For the quantum-mechanical gas-phase calculations, the single molecules were generated from the cif files considering only the atoms with higher occupancies for the compounds 2.MeOH and 4.DMF.

\section{Results and discussion}

$\mathrm{NO}_{2}$-functionalized complexes $\mathbf{2 - 5}$ and $\mathbf{6}$ were synthesized in $60-85 \%$ yields by following a well-established procedure that was not further optimized; ${ }^{2,3}$ good quality single crystals for all the species were obtained by the slow evaporation of a concentrated solution of the corresponding complex. The crystal structures of six novel uranyl-salophen complexes, $2 \cdot \mathbf{M e O H}$, 2-EtOH, 3·MeCN, $4 \cdot \mathrm{DMF}, \mathbf{5} \cdot \mathbf{H}_{\mathbf{2}} \mathrm{O}$, and $\mathbf{6} \cdot \mathrm{DMF},{ }^{19}$ as obtained by XRD analysis of a single crystal, are shown in Fig. 3. As expected, all the structures showed the $\mathrm{UO}_{2}$ centre coordinated at its equatorial plane by the tetradentate salophen ligand and by a solvent molecule (methanol, ethanol, acetonitrile, DMF, or water), ${ }^{20}$ whereas the two uranyl oxygens reside at the apical positions of the $\mathrm{U}$ atom. In the case of complex 2, two structures, 2.EtOH and $\mathbf{2} \cdot \mathbf{M e O H}$, one with ethanol and the other with methanol as the coordinated solvent, were obtained. Complex 6 was considered to have a more direct comparison with complex $\mathbf{5} \cdot \mathbf{H}_{2} \mathbf{O}$ and its single crystals, as $\mathbf{6} \cdot \mathbf{D M F}$, were also obtained and analysed by XRD.

The distinctive reduction of the ligand curvature described earlier for 2.EtOH (Fig. 2) was also observed, although to different extents, in all of the $\mathrm{NO}_{2}$-functionalized derivatives. A search of the Cambridge Structural Database (CSD) ${ }^{21}$ on salophen- $\mathrm{UO}_{2}$ complexes confirms the presence of a marked curvature in all the previously deposited entries. ${ }^{22} \mathrm{~A}$ plot of the angle $\phi$ parameter observed for all the CSD entries (reported with their CDCC code) and for the novel $\mathrm{NO}_{2}$-derivative structures $\mathbf{2} \cdot \mathbf{M e O H}, \mathbf{2} \cdot \mathbf{E t O H}, \mathbf{3} \cdot \mathbf{M e C N}, \mathbf{4} \cdot \mathbf{D M F}$, and $\mathbf{5} \cdot \mathbf{H}_{2} \mathrm{O}$ (in red) is presented in Fig. 4 (data for 6 is also shown in black). ${ }^{23}$ The average $\phi$ value for the already reported complexes (including 6.DMF) is $c a \cdot 111^{\circ}$, whereas complexes $\mathbf{2} \cdot \mathbf{M e O H}$, 2.EtOH, 3.MeCN, $\mathbf{4} \cdot \mathbf{D M F}$, and $\mathbf{5} \cdot \mathbf{H}_{\mathbf{2}} \mathbf{O}$ display an average $\phi$ value equal to ca. $130^{\circ}$, which corresponds to an approximately $20^{\circ}$ higher angle between the planes of the two external aromatic rings and a significant decrease in the structural curvature. The observation of this evident, recurring difference, which appears to be caused by the presence of the $\mathrm{NO}_{2}$ groups, is unprecedented.

As for packing motifs, all the considered structures, with the exception of $\mathbf{1} \cdot \mathbf{M e C N}$ (YALSOU, space group $\mathrm{Ccm}_{1}$ ), belong to the triclinic $P \overline{1}$ crystal system and show one independent fragment in the asymmetric unit $\left(Z^{\prime}=1\right)$ and two molecules in the unit cell $(Z=2)$. There is evidence of several nonclassic hydrogen bonds $(\mathrm{HB})^{24}$ of the $\mathrm{C}-\mathrm{H} \cdots \mathrm{O}$-type confining to the molecular backbones. All the considered compounds were characterised by a vast network of $\pi$-stacking interactions, with a minor contribution from T-shaped interactions, which strongly contribute to the overall stability of their structures. Selected stacking arrangements for 2-EtOH, $2 \cdot \mathbf{M e O H}, 3 \cdot \mathbf{M e C N}$, and 4.DMF are depicted in Fig. 5, wherein closest intermolecular contacts are indicated (cyan lines). More details can be found in the ESI. $\dagger$

Importantly, in the case of the structures of $2 \cdot \mathbf{M e O H}$, 4.DMF, and $\mathbf{5} \cdot \mathbf{H}_{2} \mathbf{O}$, i.e. those which crystallize together with solvent molecules, there is a minor contribution from some 

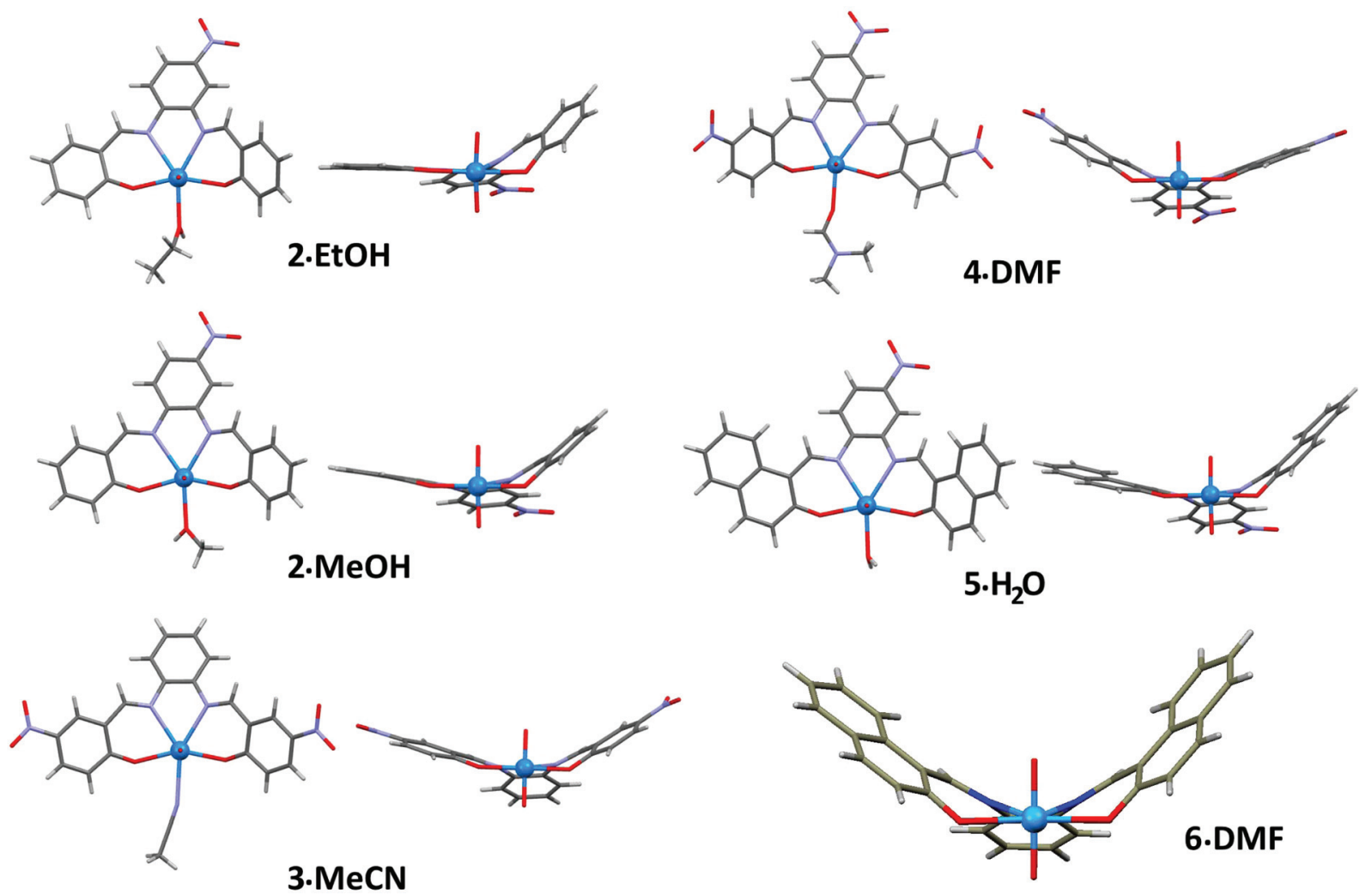

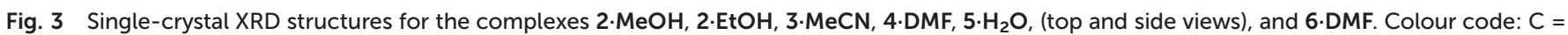
grey, $\mathrm{H}$ = light grey, $\mathrm{N}=$ blue, $\mathrm{O}=$ red, and $\mathrm{U}=$ cyan; in the side views, the uranyl coordinated solvent molecules are omitted for clarity.

classic $\mathrm{O}-\mathrm{H} \cdots \mathrm{O}$ HB. Although weak, they are not negligible and contribute to determining the final layout of the crystal packing (see ESI $\dagger$ ). Furthermore, a head-to-tail dipole interaction is present in every considered crystal structure. Finally, by a closer inspection of the $\mathrm{NO}_{2}$ conformation, it was evident that this group is almost flat - i.e. with very little tilt angle with respect to the aromatic ring to which it is attached. This clearly ensures the most efficient charge delocalization along the entire molecular backbone. This behaviour takes place even in the case of a possible overlapping of these highly charged groups at the borders of the unit cell, as reported in

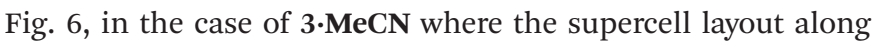
the $a$-axis projection is shown.

The question arising from these findings is related to whether the increased planarity is caused by electronic effects exerted by the strongly electron-withdrawing $\mathrm{NO}_{2}$ group (direct electronic effect) or, more simply, by its steric features, which can influence the crystal packing. To shed light on this dilemma, we carried out a series of detailed computational studies. We started with MD simulations performed using a robust approach, ${ }^{25}$ which has already been proved to be extremely reliable to extract and study the anisotropic displacement parameters (adps). ${ }^{17,26} \mathrm{MD}$ simulations with a force field (FF) representation of uranyl ion $\left(\mathrm{UO}_{2}\right)^{2+}$ have also been proven to be successful in describing the uranyl-calix[6]arene and $n$-octyl (phenyl)- $N, N$-diisobutylcarbamoylmethylphosphine oxide
(CMPO) complexes, ${ }^{27}$ as well as the interaction between uranyl ions and lipid membranes. ${ }^{28}$ In the latter studies, the uranyl moiety was treated as a rigid group with fixed bond $(\mathrm{U}=\mathrm{O})$ lengths and $(\mathrm{O}=\mathrm{U}=\mathrm{O})$ angles.

Using an FF-based approach described in the Experimental section, we simulated, in very fine detail, the characteristic structural features of all the abovementioned compounds 1-6, focusing on a correct description of their planarity/curvedness. Moreover, as MM does not take into account any electronic effect - at least not directly and not in an explicit manner - the obtained data become quite relevant for understanding the most relevant factors. Due to the complexity of our analysis, we started our study by trying to validate our computational approach, thus checking the ability of our algorithms to reliably mimic the experimental landscape inferred by single crystal XRD. To achieve this goal, we focused our attention on compound 2-EtOH. There are two main reasons for this choice. Although it is partially disordered (the central benzene ring has two possible dispositions with fractional occupancies of 0.123 and 0.877 ), (i) 2.EtOH contains only one $\mathrm{NO}_{2}$ group (Scheme 1) and, unlike other reported compounds, (ii) no solvent molecules are present in the lattice. The first characteristic (i) ensures the most asymmetric layout for the compound, thus exasperating the possible difference between the curvature of the two wings due to the presence of the $\mathrm{NO}_{2}$ group; the second feature (ii) obviously allows an easier definition of 

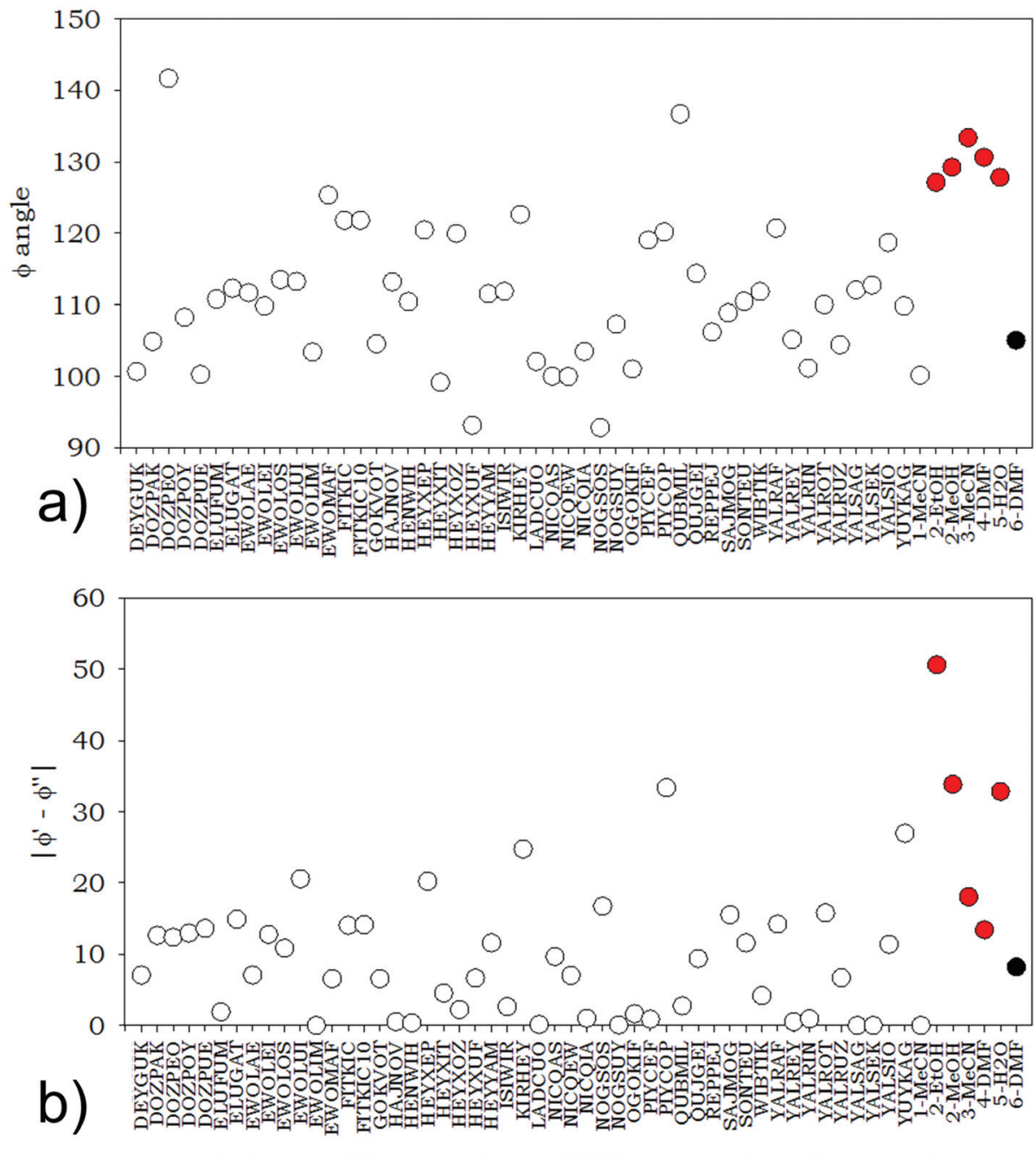

Salophen- $\mathrm{UO}_{2}$ complexes (CSD code or from Scheme 1)

Fig. 4 Plots of (a) $\phi$ values and (b) $\left|\phi^{\prime}-\phi^{\prime \prime}\right|$ values for all relevant previously reported salophen- $\mathrm{UO}_{2}$ complexes (O), with their CSD code, and for complexes 2-5 (๑) and $6(\bullet)$.

the calculated properties without the possible bias introduced by a solvent. Furthermore, a successful simulation of this disordered structure, which undoubtedly represents a challenging task, would strengthen on one hand the validity of our computational approach, whereas on the other hand, it could give us key structural information about the nature of the disorder. ${ }^{26 b}$ Thus, after having relaxed the already low symmetry of the structure, to gain the maximum freedom in the atom oscillation along the entire simulation, we set up three different approaches to study the molecule. We tried to use the information resulting from this disordered layout in the structure to support our thesis. In fact, as complex 2-EtOH is exactly disordered on the ring to which the $\mathrm{NO}_{2}$ group is attached, the first two models were obtained, simulating the disordered atoms as if they were fully present in the position belonging to their lower occupancy (0.123) first and higher occupancy (0.877) after. To achieve this, we set up a supercell with 24 molecules, whereas the original cell had $Z=2$ and $Z^{\prime}=$
1. Then, bearing in mind that the occupancy ratio is about $1: 7$, we set up a third possible cell, where 3 over 24 molecules had an occupancy of 0.123 , whereas the remaining 21 had an occupancy of 0.877 . In this way, the occupancy ratio $(1: 7)$ was also unaltered at the molecular level while filling the supercell.

Interestingly, as reported in Table 1, the energy calculations evidenced that the third structure, constructed to perfectly mimic the experimental data, containing three low occupancy and twenty-one high occupancy molecules, although it is the highest enthalpy structure, was the most stable due to entropic stabilisation. This result partially justifies the disordered layout and the fractional occupancy of the experimentally inferred unit cell.

As model 0.123 (A) is the most stable (from the enthalpy point of view), we identify our zero with its enthalpy value. Both structures, 0.877 (B) and $0.123+0.877$ (C), show a greater energy. The values of the calculated entropy $(S)$ indicate that the structure whose occupancy is 0.123 is the most ordered, 

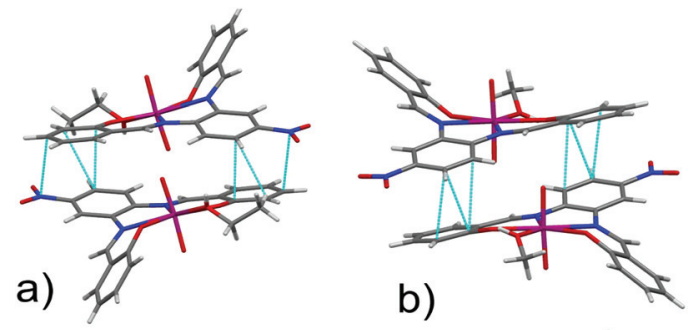

b)

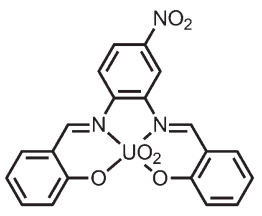

2

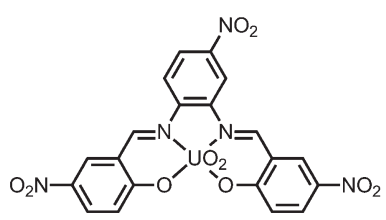

4

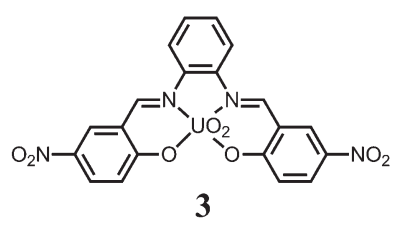

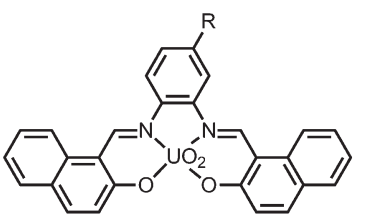

$5 \mathrm{R}=\mathrm{NO}_{2}$

$6 \mathrm{R}=\mathrm{H}$

Scheme 1 Molecular formulae of the $\mathrm{NO}_{2}$-functionalized $\mathrm{UO}_{2}$-complexes $2-5$ and 6 .

d)

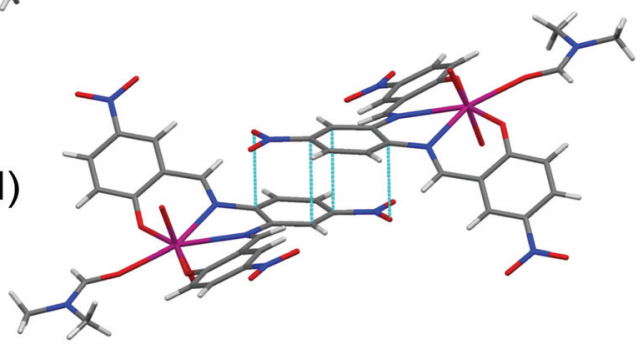

Fig. 5 Images of selected $\pi$-stacking interaction motifs for (a) 2.EtOH, (b) $2 \cdot \mathrm{MeOH}$, (c) 3.MeCN, and (d) 4.DMF. Closest intermolecular distances are indicated (cyan lines).

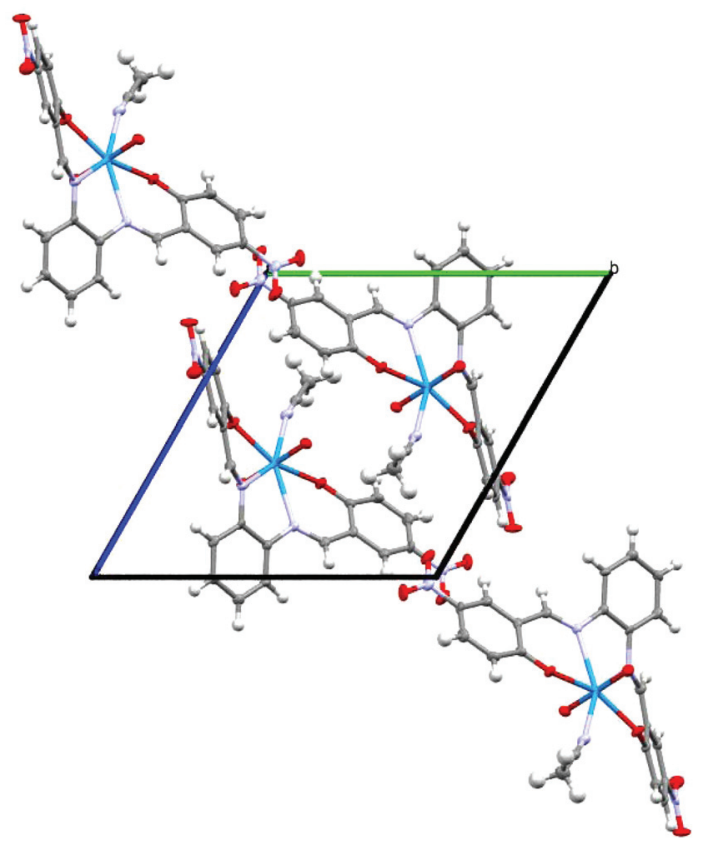

Fig. 6 3.MeCN unit-cell projection along a axis displayed together with two neighboring molecules to highlight the characteristic packing layout.

whereas in the other ( 0.877 occupancy), there is a slight increase in disorder that is magnified in the $0.123+0.877$
Table 1 Entropic, enthalpic, and overall Gibbs energy balance for the three considered structural models with different occupancies

\begin{tabular}{lllll}
\hline Model & Entropy & $\Delta H$ & $-T \cdot(123 \mathrm{~K})^{a}$ & $\Delta G$ \\
\hline A & 213.801 & 0.0 & -52.26 & -52.26 \\
B & 217.704 & 0.237 & -53.212 & -52.975 \\
C & 219.799 & 0.342 & -53.72 & -53.38
\end{tabular}

${ }^{a}$ The Boltzmann constant $k_{\mathrm{B}}$ has been taken into account.

other two, having a large number (21) of molecules with 0.877 occupancy positions, and a loss of periodicity caused by the presence of a smaller number (3) of randomly distributed molecules with 0.123 occupancy positions. The list follows the same trend as the enthalpy values, but this is inverted as the terms are negative. The calculated $\Delta G$ term is significantly affected by the entropic term, and this evidences that the $0.123+0.877$ structure, which is the experimental structure, is the most stable structure. These results were calculated at $123 \mathrm{~K}$, which is the temperature used during the crystal data collection; a fortiori, the weight of the $-T \cdot(k \cdot S)$ term will be amplified at $298 \mathrm{~K}$. It is, therefore, evident why the crystal shows this disordered layout - energetically favoured over the others - that is not due to the low quality of the crystals or incorrect experimental procedures. The satisfactory agreement between the calculated and experimental models allowed us to interpret the prevalence of the experimental disordered model over a more ordered model as a consequence of an almost unreducible static disorder, which was unaffected even after lowering the temperature.

We then compared two limiting and possibly opposite situations: the solid-state structures of 1-6 with the corresponding structures in the gas phases; i.e., with the stand-alone molecules, as inferred by HF and DFT calculations - only the latter were reported for the sake of clarity as the obtained results were very similar. The method explicitly quantifies the curvedness of the structure of the isolated molecule, i.e. it is not 
under a periodic boundary condition and therefore has no particular packing requirements. As for $2 \cdot \mathbf{E t O H}$, while the experimental parameters are $\phi=127.13, \phi^{\prime}=2.92^{\circ}, \phi^{\prime \prime}=53.51$, and $\left|\phi^{\prime}-\phi^{\prime \prime}\right|=50.59$ in the crystal, the calculated data in the gas phase are $\phi=116.14, \phi^{\prime}=33.54^{\circ}, \phi^{\prime \prime}=30.32$, and $\left|\phi^{\prime}-\phi^{\prime \prime}\right|=$ $3.22^{\circ}$, thus showing an increased curvature and a strong decrease in the difference between the two sides of the complex. A similar outcome was obtained from the calculation carried out for $\mathbf{2} \cdot \mathbf{M e O H}, \mathbf{3} \cdot \mathbf{M e C N}, \mathbf{4} \cdot \mathbf{D M F}$, and $\mathbf{5} \cdot \mathbf{H}_{\mathbf{2}} \mathbf{O}$. As for 1.MeCN, which has no $\mathrm{NO}_{2}$ group, the calculated gas-phase structure still retained a marked curvature and a fully symmetric conformation as $\left|\phi^{\prime}-\phi^{\prime \prime}\right|=0.01^{\circ}$. The very small differences between the $\phi$ parameters of $2 \cdot \mathbf{E t O H}$ and $\mathbf{1} \cdot \mathbf{M e C N}$, as calculated in the gas phase, strongly indicate that the curvature of the structure in the gas phase is not significantly affected by the presence of one or more $\mathrm{NO}_{2}$ groups. Indeed, we can roughly estimate the intrinsic effect of $\mathrm{NO}_{2}$ in 2 as a loss of ca. $3^{\circ}$ in the symmetry of the complex (as $\left.\Delta\left|\phi^{\prime}-\phi^{\prime \prime}\right|\right)$.

To further confirm the abovementioned outcomes, we also performed a HOMO-LUMO analysis and compared the molecular orbital landscape of $\mathbf{1} \cdot \mathbf{M e C N}$ and 2.EtOH. As shown in Fig. 7, the two species that differ by a $\mathrm{NO}_{2}$ group displayed no relevant differences in their HOMOs (and LUMOs, see Fig. S9, ESI $†$ ), strongly confirming the negligible effect of the electronic factors (similar results were obtained for $3 \cdot \mathbf{M e C N}$, see Fig. S9a, ESI †े).

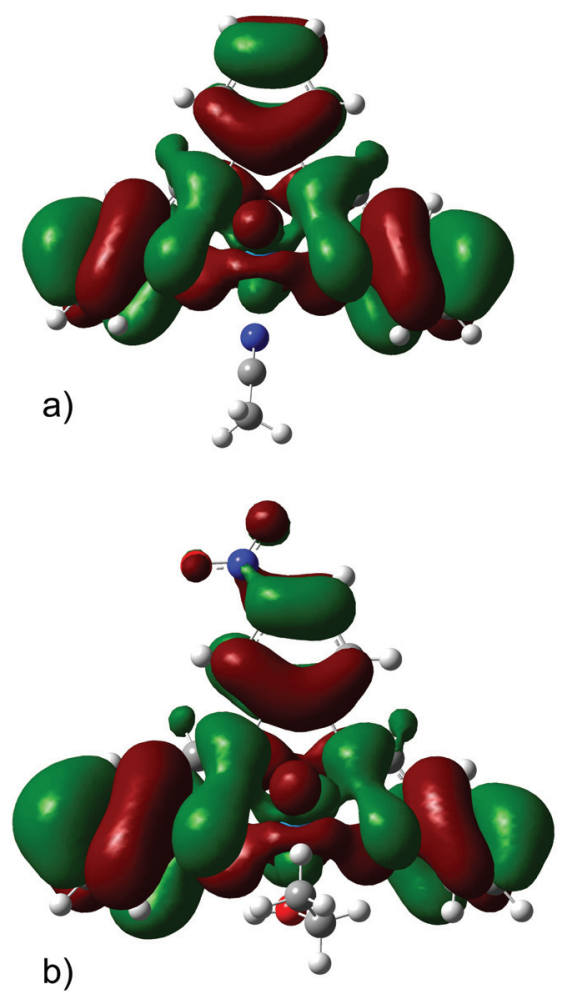

Fig. 7 1.MeCN (a) and 2.EtOH (b) HOMO isosurfaces with positive (red) and negative (green) values. Neither the presence of the $\mathrm{NO}_{2}$ group nor
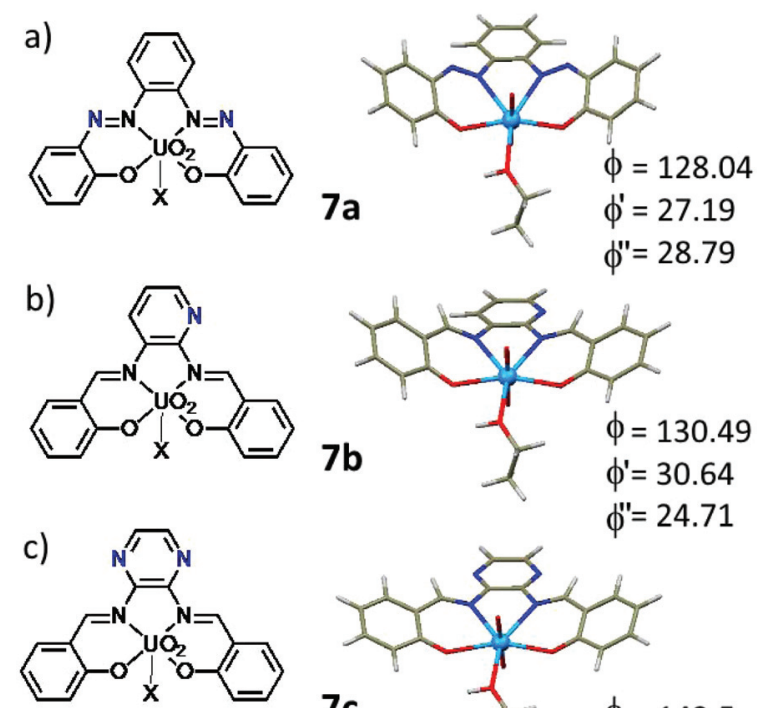

$$
\mathrm{X}=\mathrm{EtOH}
$$

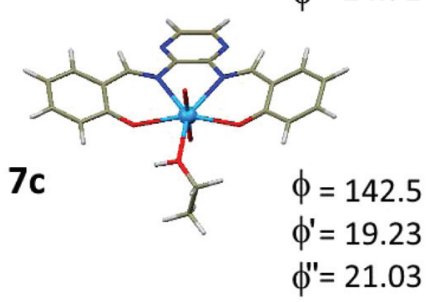

Fig. 8 Molecular formulae (left) and DFT-calculated structures with the corresponding $f$ parameters (right) for complexes (a) 7a, (b) 7b, and (c) 7c. Colour code: $\mathrm{C}=$ grey, $\mathrm{H}=$ light grey, $\mathrm{N}=$ blue, $\mathrm{O}=$ red, and $\mathrm{U}=$ cyan.

In the further DFT calculations, we evaluated the effect of the electronic factors on the curvature due to the steric clash between iminic hydrogen atoms and those on the central aromatic ring (Fig. 1c). Thus, we considered complexes $7 \mathbf{a}-\mathbf{c}$, in which the iminic $\mathrm{CH}$ or one and two aromatic $\mathrm{CHs}$ were replaced by a nitrogen atom (Fig. 8). The calculated data show that steric effects are important to the final curvature, as while going from $7 \mathrm{a}$ to $7 \mathrm{c}$, the $\phi$ values increase from $c a .128$ to $142^{\circ}$. Moreover, the lack of symmetry for $7 \mathbf{b}$ increases the $\left|\phi^{\prime}-\phi^{\prime \prime}\right|$ value to $c a .6^{\circ} .^{29}$

For the same structures, there is also evidence of a systematically longer $\mathrm{N}-\mathrm{U}$ bond on the more planar side of the molecule. Note that all the studied compounds - except for $\mathbf{3} \cdot \mathbf{M e C N}$ - evidence this peculiarity.

We then performed the same ab initio calculation after substituting the $\mathrm{UO}_{2}{ }^{2+}$ group in complex 2 with $\mathrm{Mg}^{2+}$ ion, which has a significantly smaller ionic radius. ${ }^{30}$ The resulting $\mathrm{Mg}$ salophen complex displayed a decisively more planar structure, having $\phi=160.70^{\circ}$ (Fig. S10, ESI $\dagger$ ). A similar approach was also performed via HF calculations, and the data confirmed the results obtained from the DFT approach. This is a quite interesting finding, especially considering that DFT calculations, at variance with $\mathrm{HF}$, take into account - although empirically $^{13}$ - the van der Waals dispersion effects. Interestingly, the $\mathrm{N}-\mathrm{Mg}$ bond distance, as compared to the abovementioned $\mathrm{N}-\mathrm{U}$ bond distances, is dramatically reduced from a value ranging from $2.508 \AA$ to $2.633 \AA$ to the value ranging from 2.142 to $2.152 \AA$ measured for the $\mathrm{Mg}$ compound.

Finally, dipole moment (DM) calculations were performed. As expected, the presence of generally strong dipoles in all the studied compounds where the $\mathrm{NO}_{2}$ group was present, especially when there was evident asymmetry of the $\mathrm{NO}_{2}$ 
Table 2 Dipole moments (DM) calculated at the DFT level of theory (D)

\begin{tabular}{lr}
\hline 1.MeCN & 3.8007 \\
2.EtOH & 7.8065 \\
2.MeOH & 10.0373 \\
3.MeCN & 6.4412 \\
$\mathbf{4} \cdot \mathrm{DMF}$ & 13.5391 \\
$\mathbf{5} \cdot \mathrm{H}_{2} \mathrm{O}$ & 10.1648 \\
$\mathbf{6} \cdot \mathrm{DMF}$ & 6.2101
\end{tabular}

layout, was confirmed. On the other hand, 1·MeCN (YALSOU), being symmetrical and lacking the $\mathrm{NO}_{2}$ group, in agreement with our reasoning, exhibited a lower DM value, which is approximately at least twice as small as that of the others (Table 2). The reported values evidenced a progressive change in the DM strength and consequent different tendencies to optimize the dipole interactions, which are directly correlated with the number and the more or less symmetrical arrangement of the $\mathrm{NO}_{2}$ groups. This is, at least apparently, the main driving force of the crystal packing. All complexes, except for the symmetrical 1.MeCN (YALSOU), which bears a smaller DM, show the abovementioned characteristic head-to-tail packing. The resulting energy gain favours the stabilization of the structures. This layout can be rationalized based on a triclinic symmetry for all our compounds, with the exception of the more symmetrical orthorhombic 1.MeCN (YALSOU), which in fact does not adopt this as it is not forced into the head-totail layout.

From the abovementioned results, it is quite clear that the structural features observed in complexes $2 \cdot \mathbf{M e O H}, 2 \cdot \mathbf{E t O H}$, 3.MeCN, $\mathbf{4} \cdot \mathbf{D M F}$, and $\mathbf{5} \cdot \mathbf{H}_{2} \mathbf{O}$ do not derive from the direct electronic effects due to the presence of one or more $\mathrm{NO}_{2}$ groups. Moreover, these structural features for the abovementioned compounds are strikingly different from those observed with 1.MeCN and 6.DMF and the other previously reported structures of salophen- $\mathrm{UO}_{2}$ complexes and also from those calculated for the structures in the gas phase obtained in this study. Indeed, they are more likely to be a consequence of packing effects. In this regard, strong $\pi$-stacking interactions are especially numerous and the head-to-tail arrangement of the complexes favors the correct alignment of stronger dipoles, thus leading to the more compact and flattened salophen ligand conformation. It appears not to be a coincidence that only two significant structural outliners, as shown in Fig. 4a (DOZPEO and QUBMIL), also present strong $\pi$-stacking interactions (closest atom to centroid distances in the $c a$. 3.2-3.3 Å range).

\section{Conclusion}

The single-crystal structures of a series of novel salophen- $\mathrm{UO}_{2}$ complexes 2-5 bearing one, two, and three $\mathrm{NO}_{2}$ groups were obtained. Surprisingly, they present strong deviations from the usual curvature of the salophen ligand (viz., compare average $\phi=129.6^{\circ}$ for $2-5$ with average $\phi=110.71^{\circ}$ for the previously reported structures; see Fig. 4a), which is a hallmark for the solid-state structures of this well-known class of $\mathrm{UO}_{2}$-com- plexes. The observed more pronounced flattening and concomitant conspicuous loss of symmetry in the ligand conformation is, therefore, unprecedented. These findings led us to carry out a detailed study aimed at determining by which means the $\mathrm{NO}_{2}$ groups were capable of exerting this perturbing effect that resulted in the observed solid-state structures. An integrated experimental and computational study confirms that the observed structural anomaly does not result from an intrinsic electronic effect exerted by the strongly electron-withdrawing nitro groups, but rather from the packing effects. The latter were, however, dramatically influenced by the larger DMs found for the $\mathrm{NO}_{2}$-decorated complexes, which also propagated into enhanced $\pi-\pi$ stacking interactions. Hence, the puckering of the salophen ligand, which is surely the result of the large ionic radius of the $\mathrm{UO}_{2}$ centre, can be significantly reduced by a simple chemical modification, thus demonstrating a higher than expected degree of adaptability of the salophen ligand. Considering the current interest in uranium coordination, especially for environmental remediation purposes, these data provide additional insights into the ligand/ $\mathrm{UO}_{2}$ coordination requirements, which could be useful in the ongoing search for novel and more selective U binders.

\section{Acknowledgements}

M. C. acknowledges Programma Giovani Ricercatori "Rita Levi Montalcini" 2009; A. V. and K. R. kindly acknowledge the Academy of Finland (K. R.: grants 263256, 265328, and 292746) and the University of Jyväskylä for the financial support.

\section{Notes and references}

1 (a) P. G. Cozzi, Chem. Soc. Rev., 2004, 33, 410-421; (b) C. Baleizão and H. Garcia, Chem. Rev., 2006, 106, 39874043; (c) C. J. Whiteoak, G. Salassa and A. W. Kleij, Chem. Soc. Rev., 2012, 41, 622-631.

2 M. Cametti, M. Nissinen, A. Dalla Cort, L. Mandolini and K. Rissanen, J. Am. Chem. Soc., 2005, 127, 3831.

3 (a) D. M. Rudkevich, W. P. R. V. Stauthamer, W. Verboom, J. F. J. Engbersen, S. Harkema and D. N. Reinhoudt, J. Am. Chem. Soc., 1992, 114, 9671-9673; (b) M. Cametti, L. Ilander, A. Valkonen, M. Nieger, M. Nissinen, E. Nauha and K. Rissanen, Inorg. Chem., 2010, 49, 11473-11484; (c) M. Cametti, A. D. Cort and K. Bartik, ChemPhysChem, 2008, 9, 2168-2171; (d) M. Cametti, M. Nissinen, A. Dalla Cort, L. Mandolini and K. Rissanen, J. Am. Chem. Soc., 2007, 129, 3641-3648; (e) T. Makelä, M.-E. Minkkinen and K. Rissanen, Inorg. Chem., 2016, 55, 1339-1346; (f) L. Leoni, R. Puttreddy, O. Jurcek, A. Mele, I. Giannicchi, F. Yafteh Mihan, K. Rissanen and A. Dalla Cort, Chem. Eur. J., 2016, 22, 18714-18717.

4 (a) A. Dalla Cort, L. Mandolini and L. Schiaffino, J. Org. Chem., 2008, 73, 9439-9442; (b) A. Dalla Cort, L. Mandolini and L. Schiaffino, Chem. Commun., 2005, 30, 3867-3869. 
5 J. Veliscek-Carolan, J. Hazard. Mater., 2016, 318, 266-281.

6 (a) C. A. Hawkins, C. G. Bustillos, I. May, R. Copping and M. Nilsson, Dalton Trans., 2016, 45, 15415; (b) M.-L. Feng, D. Sarma, X.-H. Qi, K.-Z. Du, X.-Y. Huang and M. G. Kanatzidis, J. Am. Chem. Soc., 2016, DOI: 10.1021/ jacs.6b07351; (c) G. Li, J. Li and Q. Han, Anal. Methods, 2016, 8, 5984; (d) J. D. Burns and B. A. Moyer, Inorg. Chem., 2016, 55, 8913-8919; (e) S. Krivovichev, P. Burns and I. Tananaev, in Structural Chemistry of Inorganic Actinide Compounds, Elsevier Science, 2007; (f) S. Beer, O. B. Berryman, D. Ajami and J. Rebek Jr., Chem. Sci., 2010, 1, 43-47; $(g)$ A. Sengupta, M. S. Murali, P. K. Mohapatra, M. Iqbal, J. Huskens and W. Verboom, Polyhedron, 2015, 102, 549-555; (h) Y. Alboa, M. Saphier, E. Maimona, I. Zilbermanna and D. Meyerstein, Coord. Chem. Rev., 2009, 253, 2049-2055; (i) M. Bühl and G. Wipff, ChemPhysChem, 2011, 12, 3095-3105; (j) E. A. Pedrick, J. W. Schultz, G. Wu, L. M. Mirica and T. W. Hayton, Inorg. Chem., 2016, 55, 5693-5701; (k) C. Priest, Z. Tian and D.-E. Jiang, Dalton Trans., 2016, 45, 9812; (l) E. Acher, Y. H. Cherkaski, T. Dumas, C. Tamain, D. Guillaumont, N. Boubals, G. Javierre, C. Hennig, P. L. Solari and M.-C. Charbonnel, Inorg. Chem., 2016, 55, 5558-5569.

7 A. Dalla Cort, L. Mandolini, G. Palmieri, C. Pasquini and L. Schiaffino, Chem. Commun., 2003, 2178-2179.

8 A. Dalla Cort, L. Mandolini, C. Pasquini and L. Schiaffino, J. Org. Chem., 2005, 70, 9814-9821.

9 The plane is defined with the $\mathrm{U}$ atom and the two equatorial oxygen atoms.

10 (a) M. Cametti, M. Nissinen, A. Dalla Cort, K. Rissanen and L. Mandolini, Inorg. Chem., 2006, 45, 6099-6101; (b) O. Signorini, E. R. Dockal, G. Castellano and G. Oliva, Polyhedron, 1996, 15, 245; (c) D. J. Evans, P. C. Junk and M. K. Smith, Polyhedron, 2002, 21, 2421-2431.

11 O. Exner and T. M. Krygowski, Chem. Soc. Rev., 1996, 25, 71-75.

12 (a) G. Schreckenbach and G. A. Shamov, Acc. Chem. Res., 2010, 43, 19-29; (b) G. Schreckenbach, P. J. Hay and R. L. Martin, J. Comput. Chem., 1999, 20, 70; (c) M. Dolg and X. Cao, Chem. Rev., 2012, 112, 403.

13 S. Grimme, Semiempirical GGA-type density functional constructed with a long-range dispersion correction, J. Comput. Chem., 2006, 27, 1787-1799; S. Grimme, S. Ehrlich and L. Goerigk, Effect of the damping function in dispersion corrected density functional theory, J. Comput. Chem., 2011, 32, 1456-1465.

14 P. Fuentealba, H. Preuss, H. Stoll and L. v. Szentpaly, Chem. Phys. Lett., 1982, 89, 418.

15 X. Li and M. J. Frisch, J. Chem. Theor. Comput., 2006, 2, 835.

16 W. D. Cornell, P. Cieplak, C. I. Bayly, I. R. Gould, K. M. Merz Jr., D. M. Ferguson, D. C. Spellmeyer, T. Fox,
J. W. Caldwell and P. A. Kollman, J. Am. Chem. Soc., 1995, 117, 5179.

17 G. M. Lombardo, A. L. Thompson, F. P. Ballistreri, A. Pappalardo, G. Trusso Sfrazzetto, G. A. Tomaselli, R. M. Toscano and F. Punzo, Dalton Trans., 2012, 41, 19511960.

18 H. J. C. Berendsen, J. P. M. Postma, W. F. van Gunsteren, A. DiNola and J. R. Haak, J. Chem. Phys., 1984, 81, 36843690 .

19 Complex 6 was previously reported in. G. Bruylants, et al., Eur. J. Org. Chem., 2012, 3570-3574. However, no characterization was presented and the cited reference for the synthesis is incorrect.

20 The identity of the solvent found coordinated to the $\mathrm{UO}_{2}$ centre depends on the crystallization conditions employed (see experimental details).

21 C. R. Groom and F. H. Allen, Angew. Chem., Int. Ed., 2014, 53, 662-671 (CSD version 5.37; May 2016 update).

22 Out of 50 entries, two outliners are present: DOZPEO and QUBMIL (vide infra).

23 The whole set of dihedrals relevant for the planarity/curvedness analysis is reported in the ESI, see Table S4. $\dagger$

24 T. Steiner, Crystallogr. Rev., 1996, 6, 1-57; G. R. Desiraju and T. Steiner, in The Weak Hydrogen Bond in Structural Chemistry and Biology, Oxford University Press, Oxford, UK, 1999.

25 G. M. Lombardo, G. Portalone, M. Colapietro, A. Rescifina and F. Punzo, J. Mol. Struct., 2011, 994, 87.

26 (a) G. M. Lombardo, A. Rescifina and F. Punzo, CrystEngComm, 2014, 16, 5917-5923; (b) G. M. Lombardo and F. Punzo, J. Mol. Struct., 2014, 1078, 158-164; (c) G. M. Lombardo, U. Chiacchio, A. Rescifina, A. Bacchi and F. Punzo, Acta Crystallogr., Sect. B: Struct. Sci., 2014, 70, 172-180; (d) A. R. Lazo Fraga, F. Furlan Ferreira, G. M. Lombardo and F. Punzo, J. Mol. Struct., 2013, 1047, 1-8; (e) V. Pistarà, G. M. Lombardo, A. Bacchi, A. Rescifina and F. Punzo, Struct. Chem., 2013, 24, 955-965; (f) G. M. Lombardo, G. Portalone, U. Chiacchio, A. Rescifina and F. Punzo, Dalton Trans., 2012, 41, 14337-14344.

27 P. Guilbaud and G. Wipff, J. Mol. Struct. (THEOCHEM), 1996, 366, 55.

28 Y.-W. Lin and L.-F. Liao, Comput. Theor. Chem., 2011, 976, 130; D. Wan, L. F. Liao, M. M. Zhao, M. L. Wu, Y. M. Wu and Y. W. Lin, J. Mol. Model., 2012, 18, 1009-1013.

29 The calculations were done with complexes $7 \mathbf{a}-\mathbf{c}$, but we consider the result applicable to all the other complexes.

30 (a) F. Corazza, C. Floriani, A. Chiesi-Villa, C. Guastini and S. Ciurli, J. Chem. Soc., Dalton Trans., 1988, 2341-2345; (b) A. Shafir, D. Fiedlerab and J. Arnold, J. Chem. Soc., Dalton Trans., 2002, 555-560; (c) P. S. Hariharan and P. A. Savarimuthu, RSC Adv., 2014, 4, 41565. 